\title{
The high price of being labelled "high risk": Social context as a health determinant for sudden unexpected infant death in Māori communities
}

\author{
Carla Houkamau ${ }^{\mathrm{A}, \mathrm{B}} \mathrm{PhD} \cdot$ David Tipene-Leach ${ }^{\mathrm{C}} \mathrm{MD} \cdot$ Kathrine Clarke $^{\mathrm{C}}$
}

${ }^{\mathrm{A}}$ Corresponding Author:

c.houkamau@ auckland.ac.nz

${ }^{\text {B }}$ Department of Management and International Business, The University of

Auckland

C Whakawhetū/ Mokopuna Ora, The University of Auckland

\begin{abstract}
:
Background: For over 25 years, nationwide efforts to address sudden infant death in New Zealand have focused on advising parents to avoid four risk factors labelled as modifiable. But Mãori infants still have sudden unexpected death in infancy (SUDI) at five times the rate of non-Māori.

Aim: This paper expands the conceptualisation of SUDI risk factors and suggests a reconsideration of the use of risk factor terminology.

Discussion: Working from the assumption that health outcomes are influenced by social determinants, we put forward two key propositions. Firstly, we argue (using maternal smoking as a case in point) that greater attention must be paid to the role of social and socio-economic factors in the prevention of SUDI in Mãori communities. Secondly, we propose that the language of risk reduction impedes Mãori engagement with health services because the discourse associated with being "at risk" and "vulnerable" casts Māori in a deficit framework affecting how Māori are perceived by health professionals and, more importantly perhaps, how Mãori see themselves.
\end{abstract}

Keywords: Sudden unexpected death in infancy, risk reduction, social determinants of health, Māori health, indigenous health, infant mortality

\section{INTRODUCTION}

New Zealand's high mortality rate from sudden infant death syndrome (SIDS), previously known as cot death, prompted the original New Zealand Cot Death Study in 1987 (Department of Health, 1991). At the time, the Māori cot death rate at 8.5/1000 was over twice the non-Māori (mainly European New Zealanders) rate at 3.5/1000. This case-control study obtained data from 485 cases (infants who died from SIDS in the post-neonatal age group), with 1800 controls (infants who were a representative sample of all hospital births in the study region) to identify risk factors. Four risk factors were deemed modifiable, that is, amenable to behavioural change. They were: prone infant sleeping position, maternal smoking, lack of breastfeeding, and bed sharing. Other risk factors that were deemed to be non-modifiable included: lower socio-economic status, unmarried motherhood, young age at first motherhood, poor maternal education, Māori ethnicity, low birth weight, prematurity and admission to infant intensive care unit (Mitchell et al., 1992). Further analysis by Scragg et al. (1993) demonstrated that the risk of bed sharing was largely confined to infants exposed to maternal smoking in pregnancy.

A national cot death prevention programme in the early 1990s highlighted the modifiable SIDS risk factors (Mitchell, Aley, \& Eastwood, 1992). These efforts resulted in a rapid decline in SIDS deaths, with a halving of the New Zealand SIDS rate within two years (Mitchell, Brunt, \& Everard, 1994); however, a very small decrease in the Māori SIDS rate over that same time, led to a huge increase in SIDS disparity. Tipene-Leach, Everard, and Haretuku (1999) said that this was because the national programme failed to plan adequately for Māori community engagement, alienated Māori by focusing on preventing bed sharing and failed to consider the role of the non-modifiable risk factors in perpetuating SIDS. Recently published data indicate that the disparity between Māori and non-Māori SIDS remains high. For example, Ministry of Health data on SUDI (defined as sudden unexplained death in infancy and includes both SIDS and accidental suffocation deaths) from 2010 to 2012 show that SUDI among Māori infants was nearly five times as high as that among non-Māori infants. This disparity was greater for females (SUDI was more than 5.5 times as likely in Māori baby girls as it was in non-Māori baby girls) (Ministry of Health, 2015; New Zealand Mortality Review Data Group, 2014).

\section{DISCUSSION}

The focus on modifiable risk factors, along with its associated discourse around "high risk", has dominated the approach of nonMāori health care providers to sudden infant death prevention over this 25-year period. The Māori SIDS Prevention Programme (Tipene-Leach, Everard, \& Haretuku, 2001) and the Whakawhetū/ Māori SUDI Prevention Programme have worked consistently to deliver SIDS and SUDI education that is responsive to Māori needs. Māori and other colleagues have developed effective SUDI interventions that are Māori specific (Abel, Stockdale-Frost, Rolls, \& Tipene-Leach, 2015; Cowan, 2010; Tipene-Leach \& Abel, 2010) and these interventions have been taken up in various forms by large-scale national providers like District Health Boards (Abel \& Tipene-Leach, 2013). 


\section{The social determinants of health}

Following Marmot's (2005) hypothesis, in this paper we reconsider the individual/risk factor focus in relation to SUDI and underline the role of socio-economic position as a major determinant of health disparities for Māori. While the risk reduction discourse implies that poor health befalls individuals due to their own behaviour and volition (Rosenberg, 1986), the social determinants of health (SDH) perspective recognises neighbourhood deprivation, income, employment status, housing, education, negative stereotyping and racial discrimination all have a role to play in individual health and behaviour. From this position, social inequality is conceptualised as a "distal" risk factor (i.e., structural and contextual) for events such as SUDI because poverty shapes the contexts in which people live and therefore their behaviour.

To clarify the link between macro-inequalities and behaviour, Sanders-Phillips, Settles-Reaves, Walker, and Brownlow (2009) set out to provide an illustration of the chain of causation. For example, exposure to racism at the macro-system (structural) level via media stereotypes and educational policies that disadvantage specific groups, give rise to childhood experiences of interpersonal discrimination and poorer quality education. These, in turn, compromise educational outcomes and perpetuate poverty and inequality by limiting access to well-paid work and good quality housing. Childhood poverty and neighbourhood deprivation are linked to risk taking during young adulthood (such as drug use, alcohol use and smoking). Young adults living in impoverished homes are also more likely to be exposed to violence and chronic illnesses. Those in poverty are less likely to have stable home environments and reliable, secure accommodation and may have little choice over their living circumstances (e.g., may live in overcrowded homes, exposed to smoking). All of these things that create SUDI risk originate outside an individual's sphere of influence. However, rather than referring to them as modifiable or not, the SDH approach shifts the focus to understanding how "upstream" societal influences (distal factors) shape "downstream" or proximal factors, thereby affecting population health (Krieger, 2008). The SDH approach therefore draws attention away from "counting risk factors" to the importance of the health consequences of environmental, social and economic policies and the need for the government, policy makers and communities to improve the underlying conditions that impact the health of populations (Williams, Costa, Odunlami, \& Mohammed, 2008).

\section{Maternal smoking and its social determinants}

Maternal smoking (especially in pregnancy) illustrates the link between distal and proximal risk factors. The SDH approach demonstrates how this poor (and seemingly irrational) health choice is perpetuated by compelling social and economic forces over which the individual pregnant woman or mother has little influence, and of which she has little conscious awareness.

The risk of SIDS increases significantly with maternal smoking in pregnancy and with bed-sharing when the mother smoked in pregnancy (Mitchell \& Milerad, 2006; Mitchell, Tuohy, Brunt, \& Thompson, 1997). The high Māori SUDI rates have been attributed primarily to bed-sharing where there was smoking in pregnancy (Abel \& Tipene-Leach, 2013; Ball \& Volpe, 2013). As a population, Māori smoking rates are higher than non-Māori, with $32.7 \%$ of Māori (aged 15 or older), compared with $13.9 \%$ of non-Māori, smoking (Johnston \& Singh, 2014). However, in pregnancy, $39 \%$ of Māori women smoke, compared with $13 \%$ of non-Māori (Broughton, 1996; Dixon, Aimer, Fletcher, Guilliland, \& Hendry, 2009; Glover, 2007). Smoking when pregnant is a socially disparaged activity (Marsh, Robertson, \& Cameron, 2014) and smokers are typically blamed and condemned for their own behaviour.

So why do Māori women smoke while pregnant? Nicotine addiction is the fundamental reason that individuals persist in using tobacco products. Accordingly, smoking is increasingly seen as a disease of physical and psychological dependency which is extremely difficult for individuals to break (Centers for Disease Control \& Prevention, 2010). Individuals must be highly motivated and intensely supported in their smoking cessation efforts in order for those efforts to be successful (Ministry of Health, 2011). This requires an understanding of smoking behaviour as it occurs in context.

Smoking is inextricably linked with poverty. The World Health Organization, in an exhaustive and methodologically rigorous systematic review examining the relationship between smoking and poverty internationally, demonstrated a strong inverse relationship between income level and tobacco use (Institute for Clinical Effectiveness and Health Policy, 2011). All over the world, poorer people smoke and are the least likely to quit. Those with a higher income are more likely to have access to educational messages, practical support and material resources to quit, while those living in poverty are less likely to access these resources and live within social contexts that support smoking behaviour (Twyman, Bonevski, Paul, \& Bryant, 2014).

In New Zealand, Māori smoking and poverty also go hand in hand. Tellingly, the 2012/13 New Zealand Health Survey found that Māori living in affluent neighbourhoods did not have higher levels of smoking than Europeans living in the same areas (Ministry of Health, 2014). Māori residing in high income North Epsom (in Auckland) had the same likelihood of being a daily smoker as nonMāori living in the same area (8-9\%). Yet, approximately $40 \%$ of Māori living in lower income Manurewa smoked. These data draw attention to the role of impoverished environments which put Māori at risk for smoking (Carroll, Casswell, Huakau, HowdenChapman, \& Perry, 2011).

What is it about poverty which places Māori at risk of smoking? Psycho-social factors need to be taken into account. Twyman et al. (2014) showed that those with higher incomes are more likely to set longer-term health goals, while those living in poverty are more likely to be living under conditions of chronic stress, without the additional psychological resources to motivate them to engage in preventative health behaviours. For Māori, the chronic stressors of poverty are amplified by social marginalisation. Indeed, a significant body of research has demonstrated that racism towards Māori is commonplace in contemporary New Zealand society and that Māori experience stigma and stereotyping, which diminish their occupational, educational and social opportunities (Kearns, Moewaka-Barnes, \& McCreanor, 2009; McCreanor, 1995, 1997; McCreanor et al., 2014; Moewaka Barnes, Taiapa, Borell, \& McCreanor, 2013). Institutional and interpersonal discrimination have also been associated with stress, which may also reinforce smoking as a behaviour (Brondolo et al., 2015).

Notably, Māori mothers are over-represented in the solo parent population and are more likely than non-Māori to have children young (i.e., in their late teens and early 20s) (Statistics New Zealand, n.d.). Younger Māori have been found to have particularly poor health literacy and are more likely to have no educational qualifications (Sarfati \& Scott, 2001; Statistics New Zealand, 2015). Young, single Māori mothers in lower socioeconomic neighbourhoods are likely to experience multiple social and psychological stressors on top of financial concerns 
(McManus, Abel, McCreanor, \& Tipene-Leach, 2010). Childcare responsibilities coupled with social isolation mean that smoking may become a strategy to cope with the stress of their daily realities.

An historical perspective on the issue has been offered by Turia (2013), who ties higher levels of smoking among Māori to the Pākehā (European New Zealander) colonisation of New Zealand. Early colonialists used tobacco to buy Māori land and this created an intergenerational legacy of smoking addiction which predisposes Māori to having higher rates of smoking than other ethnic groups in New Zealand (Broughton, 1996). Further, Blakely, cited in Johnston and Singh (2014), suggests that smoking has become normative among Māori and is therefore transmitted from one generation to the next - like a disease.

\section{What these studies tell us is that social, historical, psychological and economic factors confer a powerful distal influence on Māori women and these factors in combination compel and perpetuate smoking behaviour.}

All these factors in combination underpin higher levels of smoking among Māori - including pregnant women. Glover and Kira (2011) demonstrated, in a study of 60 pregnant Māori women aged 17-43 (Glover, 2004), that smoking was a widely accepted and normalised aspect of their social life. For example, $67 \%$ of their partners smoked - and $100 \%$ of the women lived with at least one other smoker. Importantly, women did not fully understand how damaging their smoking behaviour was for themselves and their babies. They reported feeling healthy and had no negative health symptoms which would trigger concern.

What these studies tell us is that social, historical, psychological and economic factors confer a powerful distal influence on Māori women and these factors in combination compel and perpetuate smoking behaviour (Blakely, Fawcett, Hunt, \& Wilson, 2006). Māori mothers who are told to stop smoking by health professionals may feel unmotivated to do so if they are not experiencing any negative side-effects of smoking, use smoking to reduce stress and have close relationships with other people who smoke.

To date, not enough support has been given to Māori women nationwide in the area of smoking cessation. In the study of 60 pregnant Māori women, of mainly lower socio-economic status (Glover, 2004), Glover found any smoking cessation support given to pregnant Māori women was provided "too little - too late" and information was often obscure and unclear. She found some were told to cut down rather than quit; others were told not to quit (as withdrawal symptoms could stress the baby); and many believed they could not use nicotine replacement therapy while pregnant.

The SDH perspective calls for addressing the issue on multiple levels, such as providing Māori women with the means to combat the physical addiction to nicotine as well as accurate information about the dangers of smoking/smoking when pregnant. Efforts should be focused on improving health professionals' ability to offer quit advice to Māori in a way which is appropriate and in keeping with Māori sensibilities (Ministry of Health, 2003). This may mean taking advantage of existing communication networks and leaders in Māori communities and developing age-appropriate messages through communication channels which Māori find appealing (including social networking sites which young Māori may be more responsive to). Supporting young Māori women to quit before they are pregnant (using school-based interventions), and delivering smoking cessation support to whānau (rather than just individuals) may also be more effective (Glover, 2000). In addition, Māori women may benefit from additional social and practical support over sustained periods, along with stress management techniques to cope with stressors that perpetuate the desire to smoke.

In summary, maternal smoking among Māori is embedded in an entire way of life, making it part of a social system, and smoking needs to be addressed as part of this social system in order to change (Lynch, Kaplan, \& Salonen, 1997). Referring to maternal smoking in the Māori community as a "modifiable" risk factor detracts from the social context in which Māori women smoke.

\section{The high price of being labelled "high risk"}

A second way in which the discourse of "risk" creates a social milieu, in which Māori health is jeopardised, relates to how Māori are perceived by health professionals. References to Māori being "high risk" for poor health, and the implied status of being a "burden" on New Zealand's health system, permeate government policy and research (Ministry of Health and Accident Compensation Corporation, 2013). Once Māori are labelled "at risk", the associated stereotypes of being "hard to change", "hard to reach" and "vulnerable" further compound the problem and add to the view that Māori and Māori health problems are "nonmodifiable". The negative labelling of Māori is bolstered by New Zealand's mainstream media in which Māori are often portrayed as overweight, unhealthy (Jackson, 2013), lacking in self-care and "choosing" to not access medical services that would benefit them (Hodgetts, Masters, \& Robertson, 2004).

Gregory et al. (2011) have shown that images, words and concepts associated with Māori, which repeatedly emphasise Māori vulnerability, risk and poor health, have a detrimental impact on Pākehā perceptions of Māori and justify racism and discrimination towards Māori. Insights from social psychology endorse the view that risk discourse may augur unfavourably for Māori. For example, research has shown that there is a tendency for confirmation bias to accompany labels - that is, once a person is labelled, they are typically perceived by others in ways which verify that label. It is important therefore to recognise that the people we label "at risk" seem even more "hard to reach" and "vulnerable" simply because we have labelled them so (Darley \& Gross, 1983; Eberhardt, Dasgupta, \& Banaszynski, 2003; Rosenthal \& Jacobson, 1992).

The term "self-fulfilling prophecy" was coined by Merton (1968), who defined it as a statement which alters actions, therefore causing the statement to become true (Merton, 1968; Shapiro, 1999; Steele \& Aronson, 1995; Wilkins, 1976). The potential for this concept to apply to Māori was revealed by Jansen, Bacal, and Crengle (2009), who found that financial difficulties were not the only reason Māori did not go to the doctor. Māori reported that a key deterrent was embarrassment and a fear of being patronised. This suggests Māori felt judged by health professionals and would rather go without treatment than subject themselves to this. Health care practitioners may perceive this behaviour in terms of Māori being less proactive, which they (Māori) then mirror themselves. The Māori Asthma Review (Pomare et al., 1991) found similar data and noted that Māori respondents often expressed a sense of apprehension and fear of being intimidated by doctors - an understandable response to negative experiences of being judged for making health choices identified as risky and irresponsible. 
The experiences of Māori, which emerged in the Māori Asthma Review, align with international research which demonstrated the powerful role of negative stereotypes on health seeking behaviour. For example, in a study conducted in Glasgow, Richards, Reid, and Watt (2003) compared the relationship between self-blame and ill health among 60 respondents (30 from a socio-economically deprived area and 30 from an affluent area). Data analyses found that a doctor's perceived emphasis on risky and unhealthy behaviours deterred patients from seeking medical care - because the doctor's emphasis on patient's "unhealthy" behaviours caused patients to self-blame for their own ill health. Self-blame and fear of blame and judgement on the part of healthcare workers were most common among respondents who lived in lower socioeconomic areas. Respondents from poorer neighbourhoods also reported believing that because they were responsible for their ill health, health professionals would be able to do little to help them. Those from more affluent areas were less likely to self-blame for their poor health and more comfortable seeking health care.

\section{A holistic approach is required; one which considers the social milieu of the smoking mother and the social determinants of health that predispose younger Māori women to start smoking in the first place.}

Taking into account these data, we believe Māori pay a high cost for being labelled "high risk". Negative health stereotypes attached to Māori, coupled with a focus on unhealthy lifestyle choices (i.e., risky health behaviours), may deter Māori from seeking health care in the first place. In addition, the labelling of Māori as being "high risk" for poor health may encourage health providers to develop a fatalistic attitude toward Māori, thinking that nothing they do will change the behaviour of their Māori clients.

\section{CONCLUSION}

New Zealand researchers have been successful in identifying risk factors for sudden infant death. To date, sudden infant death prevention strategies have focused almost exclusively on trying to change parents' "risky" infant raising practices. This has meant, however, that there has been little appreciation of the intimate connection between social environments and behaviour and its importance in a high SUDI risk context. Māori women who experience SUDI are more likely to live under conditions of serious deprivation and to experience alienation, marginalisation and exclusion in New Zealand society. Continuing to treat these distal risk factors as non-modifiable detracts from focusing on preventative approaches to Māori health that aim to improve the conditions in which Māori mothers live and raise their babies (McManus et al., 2010).

What is it about poverty that means Māori lack the education, the opportunity and the material, social and psychological resources to make optimal health decisions, including decisions about smoking in pregnancy? A holistic approach is required; one which considers the social milieu of the smoking mother and the social determinants of health that predispose younger Māori women to start smoking in the first place. In addition, much more work needs to be done to explore and develop interventions which de-normalise smoking in the environments of Māori women. Glover (2000) suggests that Māori themselves need to control the allocation of resources and the content and focus of education and public health prevention activities for Māori - as Māori are acutely aware of how to deliver and design healthcare services and interventions that are culturally specific and thus more likely to be effective.

Finally, we propose the language associated with "risk reduction" may impede Māori health service engagement because the discourse of "risk" and "vulnerability" places Māori within a deficit frame and jeopardises how Māori are perceived by health professionals. This position places a very different lens on language - and suggests that risk discourse actually perpetuates Māori disengagement with mainstream health services. How can we recast risk factors so that they are seen as hazards that have been created by external forces which are distal to individuals and determine proximal (behavioural) risk factors? These kinds of questions shift attention from the individual to the distal socioeconomic determinants which create lack of housing, education, employment - and the social system which fails to provide these things for Māori people to the same level that non-Māori enjoy. Further consideration is demanded; new questions must be asked and a new language should be developed.

\section{ACKNOWLEDGEMENTS AND CONFLICT OF INTEREST STATEMENT}

The authors state that there are no identifiable conflicts of interest.

\section{REFERENCES}

Abel, S., Stockdale-Frost, A., Rolls, R., \& Tipene-Leach, D. (2015).

The Wahakura: a qualitative study of the flax bassinet as a sleep location for New Zealand Māori infants. The New Zealand Medical Journal, 128(1413), 2-9.

Abel, S., \& Tipene-Leach, D. (2013). SUDI prevention: A review of Māori safe sleep innovations for infants. The New Zealand Medical Journal, 126(1379), 86-94.

Ball, H., \& Volpe, L. (2013). Sudden Infant Death Syndrome (SIDS) risk reduction and infant sleep location - moving the discussion forward. Social Science \& Medicine, 79, 84-91.

Blakely, T., Fawcett, J., Hunt, D., \& Wilson, N. (2006). What is the contribution of smoking and socioeconomic position to ethnic inequalities in mortality in New Zealand? The Lancet, 368(9529), 44-52.

Brondolo, E., Monge, A., Agosta, J., Tobin, J. N., Cassells, A., Stanton, C., \& Schwartz, J. (2015). Perceived ethnic discrimination and cigarette smoking: examining the moderating effects of race/ethnicity and gender in a sample of Black and Latino urban adults. Journal of Behavioural Medicine, 38(4), 689-700.

Broughton, J. (1996). Puffing up a storm. Volume I-Kapai te torori! Dunedin: University of Otago.

Carroll, P., Casswell, S., Huakau, J., Howden-Chapman, P., \& Perry, P. (2011). The widening gap: Perceptions of poverty and income inequalities and implications for health and social outcomes. Social Policy Journal of New Zealand, 37, 111-123.

Centers for Disease Control and Prevention (US). (2010). How tobacco smoke causes disease: The biology and behavioral basis for smokingattributable disease: A Report of the surgeon general. Atlanta (GA): Centers for Disease Control and Prevention (US); 2010. 4, Nicotine Addiction: Past and Present. Retrieved from http://www.ncbi.nlm.nih.gov/books/ NBK53018/

Cowan, S. (2010). Creating Change: How Knowledge Translates into Action for Protecting Babies from Sudden Infant Death? Current Pediatric Reviews, 6(1), 86-94.

Darley, J., \& Gross, P. (1983). A hypothesis-confirming bias in labeling effects. Journal of Personality and Social Psychology, 44(1), 20-33.

Department of Health. (1991). The New Zealand Cot Death Study (1991). Information for health workers. Wellington: Ministry of Health. Retrieved from http://www.moh.govt.nz/notebook/nbbooks.nsf/0/9da99 03ff99adea14c2565d70018cc75/\$FILE/Cot\%20death.pdf

Dixon, L., Aimer, P., Fletcher, L., Guilliland, K., \& Hendry, C. (2009). Smoke free Outcomes with Midwife Lead Maternity Carers: An analysis of smoking during pregnancy from the New Zealand College of Midwives midwifery database $2004-2007$. New Zealand College of Midwives Journal, 40, 13-19. 
Eberhardt, J., Dasgupta, N., \& Banaszynski, T. (2003). Believing is seeing: The effects of racial labels and implicit beliefs on face perception. Personality and Social Psychology Bulletin, 29, 360-370.

Glover, M. (2000). The effectiveness of a Maori Noho Marae smoking cessation intervention: utilising a kaupapa Maori methodology.

Unpublished PhD Thesis, The University of Auckland, New Zealand. Glover, M. (2004). Smoking during pregnancy among Mãori women. Auckland: Social \& Community Health, School of Population Health, The University of Auckland.

Glover, M. (2007). Cessation support for pregnant women who smoke: A survey of New Zealand general practitioners and midwives, Auckland: Auckland Tobacco Control Research Centre.

Glover, M. \& Kira, A. (2011). Why Māori women continue to smoke while pregnant. The New Zealand Medical Journal, 124(1338), 22-31.

Gregory, M., Borell, B., McCreanor, T., Moewaka Barnes, A., Nairn, R., Rankine, J., ... Kaiwai, H. (2011). Reading news about Māori: Responses from non-Māori audiences. AlterNative, 7(1), 51-64.

Hodgetts, D., Masters, B., \& Roberston, N. (2004). Media coverage of 'decades of disparity' in ethnic mortality in Aotearoa. Journal of Community and Applied Social Psychology, 14(6), 455-472.

Institute for Clinical Effectiveness and Health Policy (2011). Systematic Review of the Link Between Tobacco and Poverty, Switzerland: World Health Organization. Retrieved from http://apps.who.int/iris/bitstre am/10665/44453/1/9789241500548_eng.pdf

Jackson, W. (2013). Racial stereotypes pervade. Stuff. Retrieved from http://www.stuff.co.nz/auckland/local-news/local-blogs/williejackson/8764798/Racial-stereotypes-pervade

Jansen, P., Bacal, K., \& Crengle, S. (2009). He Ritenga Whakaaro: Mãori experiences of health services. Auckland: Mauri Ora Associates.

Johnston, M., \& Singh, H. (2014). Smoking ban, ten years on: Why more Maori light up (+interactive), New Zealand Herald. Retrieved from http://www.nzherald.co.nz/nz/news/article.cfm?c_ id $=1 \&$ objectid $=11371594$

Kearns, R., Moewaka-Barnes, H., \& McCreanor, T. (2009). Placing racism in public health: A perspective from Aotearoa/New Zealand. GeoJournal, 74(1), 123-129.

Krieger, N. (2008). Proximal, Distal, and the Politics of Causation: What's Level Got to Do With it? American Journal of Public Health, 98(2), 221-230.

Lynch, J., Kaplan, G., \& Salonen, J. (1997). Why do poor people behave poorly? Variation in adult health behaviours and psychosocial characteristics by stages of the socioeconomic lifecourse. Social Science \& Medicine, 44(6), 809-819.

Marmot, M., (2005). Social determinants of health inequalities, The Lancet, 365(9464), 1099-1104.

Marsh, L., Robertson, L., \& Cameron, C. (2014). Attitudes towards smokefree campus policies in New Zealand, The New Zealand Medical Journal, 127(1393), 87-98.

McCreanor, T. (1995). Pākehā discourses of Māori/Pākehā relations. Unpublished PhD Thesis, The University of Auckland, New Zealand.

McCreanor, T. (1997). When racism stepped ashore: Antecedents of anti-Maori discourse in Aotearoa. New Zealand Journal of Psychology, 26(1), 36-44.

McCreanor, T., Rankine, J., Moewaka Barnes, A., Borell, B., Nairn, R., \& McManus, A. (2014). The association of crime stories and Māori in Aotearoa New Zealand print media. Sites: A Journal of Social Anthropology and Cultural Studies, 11(1), 121-144.

McManus, V., Abel, S., McCreanor, T., \& Tipene-Leach, D. (2010). Narratives of deprivation: Women's life stories around Maori sudden infant death syndrome, Social Science and Medicine, 71(3), 643-649.

Merton, R. (1968). Social theory and social structure. New York: Free Press.

Ministry of Health. (2003). Evaluation of Culturally Appropriate Smoking Cessation Programme for Māori Women and their Whänau: Aukati Kai Paipa 2000. Wellington: Ministry of Health.

Ministry of Health. (2011). Mãori Smoking and Tobacco Use 2011. Wellington: Ministry of Health.

Ministry of Health. (2014). Tobacco use 2012/13: New Zealand Health Survey. Wellington: Ministry of Health.
Ministry of Health. (2015). 2013/14 New Zealand health survey, Ministry of Health, Tatau Kahukura: Mãori health statistics. Wellington: Ministry of Health. Retrieved from http://www.health.govt.nz/ourwork/populations/Māori-health/tatau-kahukura-Māori-health-statistics/ nga-mana-hauora-tutohu-health-status-indicators/infant-health

Ministry of Health and Accident Compensation Corporation. (2013). Injury-related health loss: A report from the New Zealand Burden of Diseases, Injuries and Risk Factors Study 2006-2016. Wellington: Ministry of Health.

Mitchell, E., Aley, P., \& Eastwood, J. (1992). The national cot death prevention program in New Zealand. Australian Journal of Public Health, $16,158-161$.

Mitchell, E., Brunt, J., \& Everard, C. (1994) Reduction in mortality from sudden infant death syndrome in New Zealand: 1986-92. Archives of Disease in Childhood, 70, 291-294.

Mitchell, E., \& Milerad. J. (2006). Smoking and the sudden infant death syndrome. Reviews on Environmental Health, 21(2), 81-103.

Mitchell, E., Taylor, B., Ford, R., Stewart, A., Becroft, D., Thompson, J., ... Allen, E. (1992). Four modifiable and other major risk factors for cot death: The New Zealand study. Journal of Paediatrics and Child Health, 28 (s1), S3-S8.

Mitchell, E., Tuohy, P. G., Brunt, J. M., \& Thompson, J. M. (1997). Risk factors for sudden infant death syndrome following the prevention campaign in New Zealand: A prospective study. Pediatrics, 100(5), $835-840$

Moewaka Barnes, A., Taiapa, K., Borell, B., \& McCreanor, T. (2013). Māori experiences and responses to racism in Aotearoa New Zealand. MAI Journal, 2(2), 63-77.

New Zealand Mortality Review Data Group. (2014). New Zealand Child and Youth Mortality Review Committee: 10th Data Report: 2009 - 2013. University of Otago, New Zealand. Retrieved from https://secure-www. otago.ac.nz/nzmrdg/

Pomare, E., Tutengaehe, H., Ramsden, I., Hight, M., Pearce, N., \& Ormsby, V. (1991). He Mate Huango: Mãori Asthma Review. Wellington, New Zealand: Huia Publications.

Richards, H., Reid, M., \& Watt, G. (2003). Victim-blaming revisited: a qualitative study of beliefs about illness causation, and responses to chest pain. Family Practice, 20(6), 711-716.

Rosenberg, C. E. (1986). Disease and social order in America: Perceptions and Expectations. The Milbank Quarterly, 64, 34-55. doi: $10.2307 / 3350040$

Rosenthal, R., \& Jacobson, L. (1992). Pygmalion in the classroom: Expanded edition. New York: Irvington Publishers.

Sanders-Phillips, K., Settles-Reaves, B., Walker, D., \& Brownlow, J. (2009). Social inequality and racial discrimination: Risk factors for health disparities in children of color. Pediatrics, 124, S176-S186. doi:10.1542/peds.2009-1100e

Sarfati, D., \& Scott, K. (2001). The health of lone mothers in New Zealand. The New Zealand Medical Journal, 114(1133), 257-259.

Scragg, R., Mitchell, E., Taylor, B. J., Stewart, A. W., Ford, R. P., Thompson, J. M., ... Becroft, D. M. (1993). Bed sharing, smoking, and alcohol in the sudden infant death syndrome. New Zealand Cot Death Study Group. British Medical Journal, 307(6915), 1312-1318.

Shapiro, A. H. (1999). Everybody belongs: Changing negative attitudes toward classmates with disabilities. New York: Garland Pub.

Statistics New Zealand (2015). Births and deaths: Year ended December 2014. Retrieved from http://www.stats.govt.nz/browse_for_stats/ population/births/BirthsAndDeaths_HOTPYeDec14.aspx

Statistics New Zealand. (n.d.). Demographic trends: 2011. Retrieved from http://www.stats.govt.nz/browse_for_stats/population/estimates_ and_projections/demographic-trends-2011/births.aspx

Steele, C. M., \& Aronson, J. (1995). Stereotype threat and the intellectual test performance of African Americans, Journal of Personality and Social Psychology, 69(5), 797-811.

Tipene-Leach, D., \& Abel, S. (2010). The wahakura and the safe sleeping environment. Journal of Primary Health Care, 2(1), 81.

Tipene-Leach, D., Everard, C., \& Haretuku, R. (1999). Taking a strategic approach in Mãori communities - an indigenous perspective. Working paper. Department of Māori and Pacific Health, The University of Auckland. 
Tipene-Leach, D., Everard, C. \& Haretuku, R. (2001). Taking a strategic approach to SIDS prevention in Māori communities. In R. W. Byard \& H. F. Krous (Eds.), Sudden infant death syndrome: Problems, progress, and possibilities. London: Arnold.

Turia, T. (2013). Te Ara Ha Ora-Pathway to the breath of life for all. Speech delivered to Breakfast launch of the National Māori Tobacco Control Leadership Service. Retrieved from https://www.beehive.govt. $\mathrm{nz} /$ speech/breakfast-launch-national-Māori-tobacco-control-leadershipservice-te-ara-ha-ora-\%E2\% $\% 0 \% 93$-pathway-br

Twyman, L., Bonevski, B., Paul, C., \& Bryant, J. (2014). Perceived barriers to smoking cessation in selected vulnerable groups: a systematic review of the qualitative and quantitative literature. British Medical Journal Open, 4 (12). e006414. doi:10.1136/bmjopen-2014-006414

Wilkins, W. (1976). The concept of a self-fulfilling prophecy. Sociology of Education, 49(2), 175-183.

Williams, D. R., Costa, M. V., Odunlami, A. O., \& Mohammed, S. A. (2008). Moving upstream: how interventions that address the social determinants of health can improve health and reduce disparities. Journal of Public Health Management and Practice, 14(Supplement), S8-S17. doi:10.1097/01.phh.0000338382.36695.42

\section{Accepted for publication November 2016}

Houkamau, C., Tipene-Leach, D., Clarke, K. (2016). The high price of being labelled "high risk": Social context as a health determinant for sudden unexpected infant death in Māori communities. New Zealand College of Midwives Journal, 52, 56-61.

http://dx.doi.org/10.12784/nzcomjnl52.2016.9.56-61
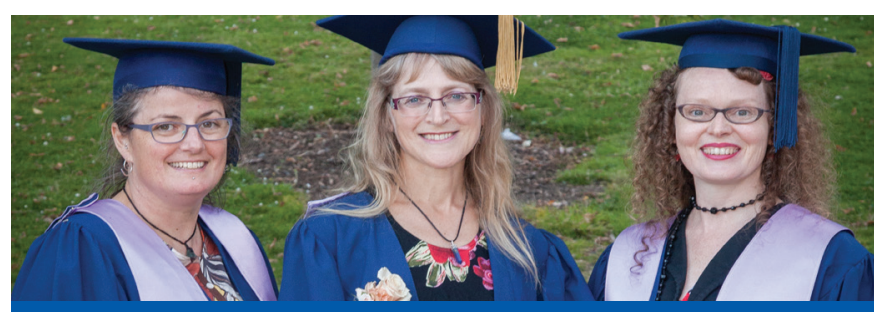

For excellence in midwifery education

Our flexible, practice-focused programmes and courses are specially designed to meet the needs of midwives and the requirements of the Midwifery Council of NZ. We are offering the following online postgraduate papers for 2017:

Feb 13 - Mar 31 Preceptorship for Midwives

Feb 13 - Mar 31 Diabetes in Pregnancy

Feb 13 - Jun 9 Knowledge and Theory in Midwifery ${ }^{\star}$

Feb 13 - Jun 9 Midwifery Assessment and Decision Making for Complexity

Apr 24 - Jun 9 Sustainability for Midwives

Apr 24 - Jun 9 Politics and Practice of Breastfeeding

Jul 10 - Aug 25 Nutrition for the Childbearing Woman

Jul 10 - Aug 25 Maternal Mental Health

Jul 10 - Nov 3 Research Methods in Midwifery Practice

Jul 10 - Nov 3 Midwifery Practicum for Complexity*

Sep 18 - Nov 3 Hypertension in Pregnancy

Sep 18 - Nov 3 What Research tells us about SUD

*Pre-thesis courses only available for those enrolled in the PG Diploma.

**The Practicum includes a personal choice elective paper. If you wish to complete the Complex Care Pathway including the Practicum, please register your interest with Suzanne Miller (suzanne.miller@op.ac.nz) as places are limited.

\section{Complex Care Midwifery Post-graduate education}

\section{(Funding now available for LMC and Core midwives)}

\begin{abstract}
A Complex Care post-graduate certificate enables midwives to develop clinical skills in specific areas.
\end{abstract}

Funding is now available to support all midwives (self-employed or employed) and covers the costs of academic fees, release for clinical placements* and academic requirements, and support for travel/accommodation (if eligible).

*Release for employed midwives is paid to DHB employers to enable "back fill" of hours. Release for self-employed midwives is paid directly to applicant to arrange own locum cover.

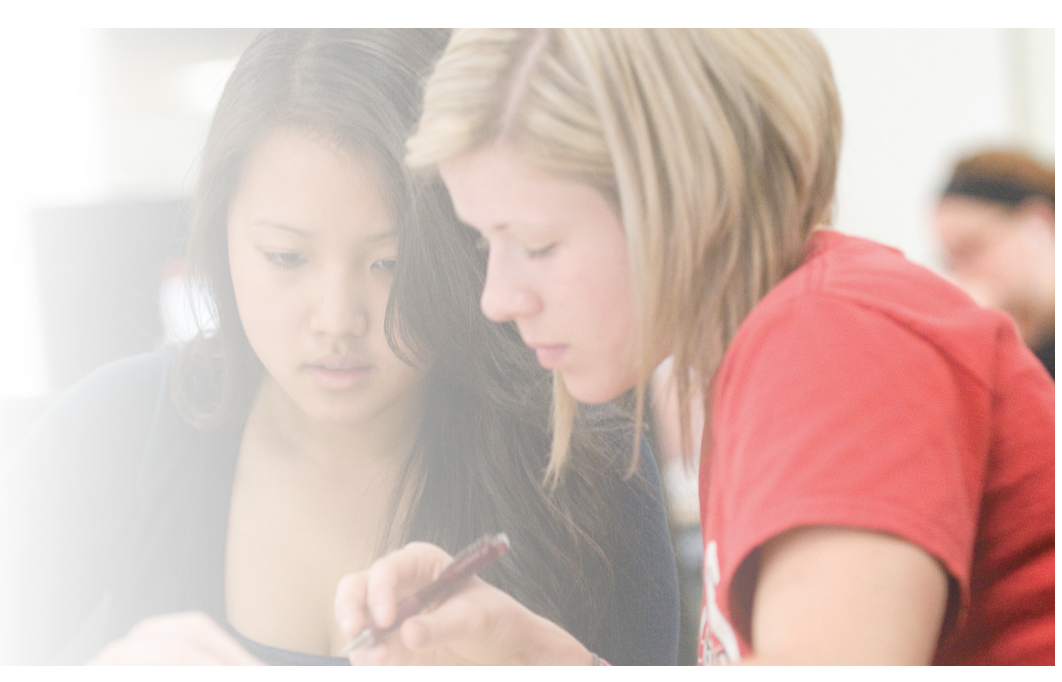

\section{How do I enrol?}

Enrolment should be made directly to the schools providing the programmes:

- Auckland University of Technology

- Victoria University Wellington

- Otago Polytechnic

\section{How do I apply for funding?}

Applications can be made from 30 November on-line via the NZCOM website www.midwife.org.nz 